\title{
Community-wide effects of marine reserves in the Mediterranean Sea
}

\author{
Paolo Guidetti ${ }^{1, *}$, Enric Sala ${ }^{2,3}$ \\ ${ }^{1}$ Laboratory of Zoology and Marine Biology, DiSTeBA, University of Salento, via Provinciale Monteroni, 73100 Lecce, Italy \\ ${ }^{2}$ Centre d'Estudis Avançats de Blanes, Consejo Superior de Investigaciones Científicas, Accés a la Cala St. Francesc, 14, \\ 17300 Blanes, Spain \\ ${ }^{3}$ Center for Marine Biodiversity and Conservation, Scripps Institution of Oceanography, La Jolla, \\ California 92093-0202, USA
}

\begin{abstract}
We investigated the community-wide effects of no-take marine reserves at the regional scale in the Mediterranean Sea. Reserves had general positive effects of protection on fish targeted by fishing, and variable effects on non-target species. Differences in the structure of fish assemblages (in terms of abundance of species and trophic groups) were greater between geographic locations than when compared among all protected and adjacent fished areas at the regional scale. These results suggest that the assemblage-wide response to protection at the species level may be spatially idiosyncratic, as a function of local factors. However, the functional (trophic group) response of the fish assemblages to protection appears to be more general. Response of fish assemblages to protection was significantly related to reserve age (i.e. duration of protection) only when evaluated at functional level, whereas reserve size did not appear to influence fish assemblages at either species or functional level. Reserves can enhance trophic cascades and ecological shifts once the density of fish predators of sea urchins reaches a density threshold of about 15 adult sea breams (Diplodus sargus and $D$. vulgaris, the most important sea urchin predators) per $100 \mathrm{~m}^{2}$. These non-linearities in the community-wide effect of reserves suggest that caution is needed in simplistically treating reserves and unprotected areas as 2 experimental treatments in ecological studies.
\end{abstract}

KEY WORDS: Marine reserves - Rocky reef fish - Reserve age and size · Sea urchins . Trophic cascades $\cdot$ Mediterranean Sea

\section{INTRODUCTION}

Marine reserves lead to increases in total abundance, biomass and size of fish within their boundaries, especially for species targeted by fisheries (Harmelin et al. 1995, Jennings et al. 1995, Mosquera et al. 2000, Micheli et al. 2004). This seems a general response independent of reserve size (Côté et al. 2001, Halpern 2003), while contrasting results have been reported with regard to reserve age (Mosquera et al. 2000, Halpern \& Warner 2002, Micheli et al. 2004, Russ \& Alcala 2004). Empirical and theoretical studies also suggest that changes in the abundance of predatory fish can cause ecosystem-wide effects such as trophic cascades (Sala et al. 1998, Pinnegar et al. 2000, Shears \& Babcock 2002, Guidetti 2006).
Most previous field studies evaluated reserve effectiveness locally (often at a single reserve, but there are exceptions; Edgar \& Barrett 1999, Willis et al. 2003, Garcia-Charton et al. 2004), and analysis of reserve effects from different studies (meta-analysis) generally assessed reserve performance on species richness, total fish abundance, and abundance of fish grouped into trophic groups or other categories (i.e. families), seldom considering community-wide effects and possible biogeographic differences in the changes at community level. Different biogeographic regions harbor different fish communities, where strongly interactive species (e.g. functionally important species) or species targeted by fishing (hereafter target species) may differ (see Pinnegar et al. 2000 and references therein). This may potentially result in different community- 
wide effects (Micheli et al. 2004). Here we address general and spatial responses to protection on fish assemblages at different levels (i.e. species and trophic groups), and related ecosystem-wide effects. We focused our study in the Mediterranean Sea in order to prevent large biogeographic differences in species pools from confounding the results of meta-analysis. In addition, we explored the likelihood of trophic cascades after protection.

Fish assemblages in Mediterranean infralittoral rocky habitats are typically composed of several tens of species, and the fish species pool is almost identical throughout the western Mediterranean basin and Adriatic Sea (Fischer et al. 1987). Although the composition of fish assemblages is similar, we know little about differences in community structure (e.g. the distribution of species abundance) at the regional scale. With regard to fish and the assessment of reserve effects in the Mediterranean Sea, many published studies have provided evidence for positive effects of protection on fish, while other studies did not find any clear benefit of protection (Bell 1983, Garcia-Rubies \& Zabala 1990, Francour 1991, 1994, Dufour et al. 1995, Harmelin et al. 1995, Vacchi et al. 1998).

Most previous studies investigated fish response to protection in single marine reserves and lacked proper replication in space (with many cases of pseudoreplication; sensu Hurlbert 1984) and time, or used inappropriate controls. In many cases, this makes it difficult to distinguish between treatment (i.e. protected vs. fished) and location (i.e. spatial variability) effects (see Guidetti 2002 and references therein). Environmental heterogeneity (e.g. habitat structure), in fact, has been found to have a marked effect on fish distribution patterns, which may in turn affect the reliability of studies where fished vs. unfished conditions are compared with insufficient replication (Garcia-Charton et al. 2000, 2004). Therefore, poor sampling designs do not allow logical distinction between protection effects on fish and the influence of the remaining sources of (often natural) variability. A few available studies investigated distribution patterns of fish in different protected and adjacent fished areas at different spatial scales (e.g. along the Mediterranean coasts of Spain; see Garcia-Charton et al. 2004) or qualitatively reviewed the available information (Garcia-Charton et al. 2000). However, no quantitative studies have assessed generalities in fish assemblage- and/or ecosystem-wide responses following the establishment of marine reserves across the Mediterranean basin, nor have they investigated fish assemblages at levels of species and functional (trophic) groups. Thus a meta-analysis approach is useful because of (1) the general absence of proper spatial replication in many previous studies and (2) a lack of comprehensive quantitative studies at a basin scale.

Benthic communities in the shallow Mediterranean rocky sublittoral have 2 extreme alternative successional endpoints: coralline barrens and complex macroalgal beds (Sala et al. 1998). When the density of sea urchin Paracentrotus lividus exceeds a threshold of 7 to 9 urchins $\mathrm{m}^{-2}$, a shift between macroalgal assemblages and coralline barrens has been observed to occur (Verlaque 1987, Hereu 2004). Several fish species can prey upon sea urchins, but 2 sparid fishes, Diplodus sargus and D. vulgaris (hereafter Diplodus; both are targeted by fishing), are the most important predators of adult urchins and the only predators that have been demonstrated to have the potential to effectively control sea urchin population density (Sala 1997, Guidetti 2006). Even though the food web of subtidal rocky reefs include complex and multiple trophic interactions, the link between predatory fish, sea urchins and macroalgae has been found to be the path through which fishing may dramatically affect the overall community (see Sala 2004). It has been suggested that the transition from macroalgal beds (which harbour hundreds of species of algae and invertebrates) to barrens (dominated by sea urchins and a few species of encrusting algae) can be enhanced by the removal of large predatory fish that feed on sea urchins, and that marine reserves may trigger the recovery of predatory fish and thus potentially re-establish their predatory control on sea urchin populations (Sala et al. 1998 and references therein, Guidetti 2006).

If marine reserves cause a recovery of predatory fish densities such that sea urchin densities are reduced below a given threshold, we would expect reserves to harbour macroalgal beds (as long as there are source macroalgal populations in or near the reserve). When predatory fish are not sufficiently abundant to reduce sea urchin densities below the threshold, as might happen in fished areas, we would expect these areas to harbour coralline barrens. Although experimental studies have shown that large size and high abundance of predatory fishes leads to high predation rates on sea urchins, factors other than protection can affect sea urchin abundance, which may be large even in marine reserves (Sala \& Zabala 1996, Sala et al. 1998, Hereu 2004, Guidetti 2006). The relationship between predatory fishes and urchins, and the existence of trophic cascades after reserve creation, are hence not easily predictable. More research from this perspective is needed to better understand why the available assessments of community-wide changes in sublittoral Mediterranean rocky reefs following protection have produced results that are - to some extent-contradictory (Sala et al. 1998, Micheli et al. 2005, Guidetti 2006). 
Table 1. Size (surface area of marine reserves and related no-take zones), year of formal establishment (which may not correspond to year when effective enforcement began) and formal reserve age at the time when data were collected

\begin{tabular}{|lcccc|}
\hline Marine reserve & $\begin{array}{c}\text { Total surface } \\
\text { (ha) }\end{array}$ & $\begin{array}{c}\text { No-take surface } \\
\text { (ha) }\end{array}$ & $\begin{array}{c}\text { Establishment } \\
\text { (year) }\end{array}$ & $\begin{array}{c}\text { Reserve age when data } \\
\text { were collected (yr) }\end{array}$ \\
\hline 1. Cabo de Gata & 12200 & 2395 & 1987 & 9 \\
2. Cabo de Palos & 1990 & 190 & 1995 & 1 \\
3. Cabrera & 8703 & 768 & 1991 & 5 \\
4. Medes Islands (1988, 1999) & 418 & 94 & 1983 & $5-16$ \\
5. Banyuls-sur-Mer (1980, 1992) & 650 & 65 & 1974 & $6-18$ \\
6. Portofino & 346 & 18 & 1998 & 5 \\
7. Cinque Terre & 2726 & 79 & 1997 & 13 \\
8. Scandola & 1000 & 72 & 1975 & 9 \\
9. Ustica Island & 15951 & 60 & 1986 & 11 \\
10. Torre Guaceto & 2227 & 179 & 1991 & 13 \\
11. Tremiti Islands & 1466 & 180 & 1989 & 16 \\
12. Miramare & 120 & 30 & 1986 & \\
\end{tabular}

This study aimed to (1) assess whether protection from fishing creates a general response in fish assemblages in the Mediterranean basin, and (2) examine the relationship between the abundance of major predatory fish and the abundance of their sea urchin prey.

\section{MATERIALS AND METHODS}

Reserve effect on fish species and trophic groups. We examined fish response to protection in 12 marine (no-take) reserves in the Mediterranean Sea (Table 1), from which data were available from both the reserves and nearby fished areas (Fig. 1). We avoided the use of data from the so-called 'paper reserves' where protection is only formal (identified as those reserves where there is no personnel devoted to enforce restrictions to fishing and where illegal fishing is known to be a common and diffuse practice). When fish density and biomass were not available in the literature, we obtained unpublished data from a number of authors. When the data originated from more than 1 protected and/or unprotected area within the same location and the data were collected at the same time, we used weighted average values (see Côté et al. 2001 for details). Whenever the data were collected in subsequent sampling occasions over a relatively short time (e.g. within the same year), we used mean values to approximate average conditions in time. In all cases, the data came from the comparison of reserves and nearby fished areas sampled at the same time. All the studies that were included used standard visual census techniques (strip transects or point counts; Harmelin-Vivien et al. 1985). Previous studies showed that the use of density values obtained from different visual census techniques have negligible effects on meta-analyses (Côté et al. 2001). We thus assumed that values standardized for a similar area of reference were comparable. When biomass data were not available, we estimated biomass using

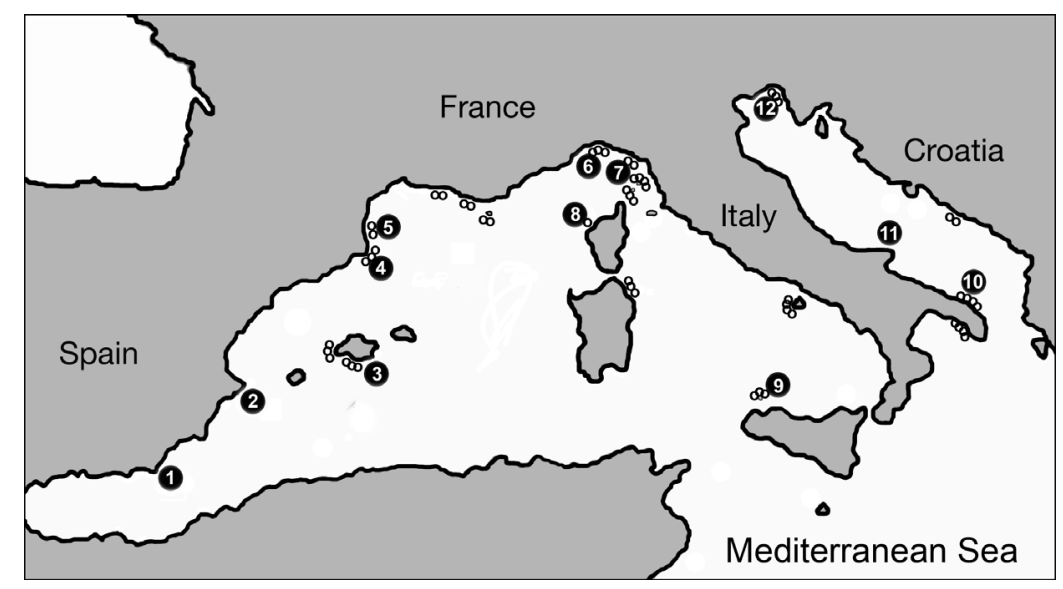

Fig. 1. Location of marine reserves and adjacent fished areas. 1, 2, 3: Cabo de Palos, Cabo de Gata, and Cabrera, respectively (García-Charton et al. 2004); 4 : Medes Islands (García-Rubies \& Zabala 1990, A. García-Rubies et al. unpubl. data); 5: Banyuls-sur-Mer (Bell 1983, Dufour et al. 1995); 6, 7: Portofino, Cinque Terre (Tunesi \& Molinari 2005, Tunesi et al. 2006); 8: Scandola (Francour 1991); 9: Ustica Island (Vacchi et al. 1998); 10, 11, 12: Torre Guaceto, Tremiti Islands, Miramare (Guidetti et al. 2005, Guidetti 2006, authors' unpubl. data). o: areas where density data on sea urchins and predatory fish were obtained (Bell 1983, Harmelin 1987, García-Rubies \& Zabala 1990, Dufour et al. 1995, Sala \& Zabala 1996, Vacchi et al. 1998, Guidetti \& Bussotti 2000, Lecchini et al. 2002, Micheli et al. 2005; F. Badalamenti, J. Coll, P. Guidetti, J. G. Harmelin, B. Hereu, M. Milazzo, M. Mori, S. Ruitton unpubl. data) 
size distributions from these studies and lengthweight relationships from the literature (Francour 1990, www.fishbase.org).

For the meta-analysis of fish response to protection, we considered only data from sublittoral rocky reefs to a maximum depth of 15 to $20 \mathrm{~m}$. Miramare was the exception, because the data come from breakwaters (made of transplanted boulders) running parallel to the coast. Because of the differences in taxonomic resolution among studies, we included in the analysis only those fish present in most (>90\%) databases: Dentex dentex, Diplodus sargus, Diplodus vulgaris, Diplodus puntazzo, Sparus aurata, Sciaena umbra, Dicentrarchus labrax, Epinephelus marginatus, Scorpaena porcus, Scorpaena scrofa, Serranus cabrilla, Serranus scriba, Mullus surmuletus and Mugilidae (common fish taxa targeted by many kind of fisheries), and Chromis chromis, Symphodus mediterraneus, Symphodus ocellatus, Symphodus tinca, Coris julis, Thalassoma pavo, Diplodus annularis, Oblada melanura and Sarpa salpa (common species of low/nil commercial value; however, some of these fish are commercialised locally). These species accounted for more than $90 \%$ of fish abundance in most locations.

We examined the response to protection on species (and for the family Mugilidae) and functional groups. Species were pooled into functional groups based on their trophic position because (1) fishing disproportionately targets species at high trophic levels, affecting the overall trophic structure of marine communities (e.g. Pauly et al. 1998), and (2) recovery from fishing potentially includes increased abundances or biomass of high-level predators and shifts in trophic structure (Micheli et al. 2004).

Each species was assigned to 1 of 7 trophic groups using the available information about diet and size in the FishBase database (www.fishbase.org) and in Mediterranean studies (Sala 2004 and references therein). These trophic groups were: large piscivores, small piscivores, invertebrate feeders Type 1 (major predators of sea urchins), invertebrate feeders Type 2 (whose diets seldom include sea urchins), detritivores, planktivores, and herbivores (see Fig. 2 for species groupings). We split invertebrate feeders into 2 groups because of the major role a few fish species can have in regulating sea urchin populations and hence in affecting the entire community (Sala et al. 1998, Hereu 2004, Guidetti 2006). Piscivores included species feeding exclusively on fish and species feeding on both fish and invertebrates (Micheli et al. 2004).

We quantified the effects of protection in reserves as the natural logarithm of the ratio between the values of the response variable (density or biomass) in reserves and those in fished areas (response ratios, $\ln R$; Hedges \& Olkin 1985, Micheli et al. 2004). Data were thus nor- malized and the response to protection examined independently of the absolute densities at each reserve. Because estimations of average values can be affected by sampling effort, we calculated weighted means using the natural logarithm of the total area covered by the censuses from which the estimates were obtained (see Mosquera et al. 2000). Other weightings were not possible because some studies reported only average abundance values. Positive response ratios indicate greater density and/or biomass of species or trophic groups in reserves than in fished areas, whereas negative values indicate greater values in fished areas compared with reserves. Averages of the mean response ratios have been considered significantly different from zero (i.e. there is a significant difference in the measured variable between treatments) when the $95 \%$ CI around the mean do not overlap with zero (Micheli 1999 and references therein). A ratio of zero thus means that densities are identical between reserves and fished areas.

Reserve effect on the structure of fish assemblages. To examine general patterns of similarity in fish assemblages between reserves and fished areas, and among (geographic) locations where reserves are located, we performed an analysis of similarity (ANOSIM) on density data of fish species and trophic groups. Analyses on biomass data were not possible because only 5 studies reported biomass or size data. Non-metric multidimensional scaling (nMDS) was used to graphically represent fish assemblages in relation to protection level (reserve/fished area) in each location considered. The similarity percentage procedure (SIMPER) was used to detect the species or trophic groups that contributed most to dissimilarity (Clarke \& Warwick 1994). These analyses were carried out considering 11 reserves, as the data set available for the Scandola reserve included only a limited subset of fish species. We included 2 fish surveys from both the Banyuls and Medes marine reserves, conducted more than 10 yr apart, as 2 different samples. To prevent the effects of the numerical dominance by non-target species (i.e. planktivorous and herbivorous fish, which include several gregarious fish species living in large aggregations) on the patterns of similarity among fish assemblages from reserves and fished areas in the various geographic locations, we ran a second series of multivariate analyses after excluding these 2 fish groups from the data sets.

To explore the community trajectory of change in reserves after protection, the best option is to monitor reserves and nearby unprotected sites several years before and after protection (Guidetti 2002). However, most available data are simply snapshot comparisons between reserves and unprotected areas (Russ et al. 2005). Nevertheless, the existing data can provide 
evidence of general trajectories of change in a multidimensional space using nMDS. For each reserve, trajectories of change in fish assemblages as a result of protection may be approximated by drawing a vector between the position of each unprotected situation and its corresponding reserve in the nMDS plot. We thus plotted centroids of fish assemblages from every fished and unfished condition and connected them in pairs, from each fished area to its adjacent reserve, using vectors. We applied this approach to both species and trophic group matrices in order to provide evidence of whether responses of fish to protection at the different reserves were more general at the functional level. We regarded results as suggestive of this hypothesis if, among reserves, trajectories of community change running from the fished to the unfished condition (i.e. direction of vectors in the multivariate space) were more consistent at trophic group than species level.

We also explored possible general responses of fish assemblages to reserve age (years since reserve creation) and size (area of the no-take zone) using a constrained ordination termed canonical analysis of principal coordinates (CAP; Anderson \& Willis 2003). CAP can uncover patterns that are masked in unconstrained ordinations (e.g. nMDS) and finds axes that maximise the degree of correlation between a set of predictor and response variables. Here, the relative importance of reserve age and size in influencing fish assemblages was assessed by virtue of the strength of their individual correlations with the canonical axes. Analyses were conducted at both species and trophic level. The canonical correlations were tested using 4999 random permutations.

Trophic cascade in the shallow Mediterranean rocky sublittoral. We examined the community-wide responses to protection in the form of trophic cascades, in this case fish-sea urchins-algae (see 'Introduction'). From this perspective, even though there is empirical evidence that abundant predatory fish populations can regulate sea urchin populations (Sala \& Zabala 1996, Sala et al. 1998, Hereu 2004, Guidetti 2006), we know little about the relationship between fish and sea urchin abundance over large spatial scales. We thus assembled data from 53 areas (including 15 reserves) throughout the Mediterranean from which data on both sea urchin and fish densities were available (Fig. 1). We assessed the effects of reserves on abundance of Diplodus and sea urchins using response ratios.

Although the sea urchin Paracentrotus lividus is the most important benthic grazer in the infralittoral of the western part of the basin, the urchin Arbacia lixula can have an equal or greater role in some southern regions (Guidetti et al. 2003). We thus examined the individual relationships between the abundance of Diplodus and the 2 sea urchin species. We first tested the signifi- cance of changes in variability of sea urchin abundance along the gradient of fish abundance using a likelihood model. Four models were compared: (1) constant mean and SD (homoscedastic), (2) constant mean and SD linearly related to fish abundance (heteroscedastic), (3) mean linearly related to fish abundance and constant SD (homoscedastic), and (4) both mean and SD linearly related to fish abundance (heteroscedastic). The analysis was repeated using raw sea urchin abundance data and log-transformed data. We used the Solver routine in Excel to minimize the sum of $[-\ln ($ Prob)] where Prob is the probability density function value for sea urchins based on the abundance, mean, and standard deviation (SD) at a given site; mean $=m \times$ number of Diplodus fish $+b$ where $m$ and $b$ are parameters determined by the routine; and $\mathrm{SD}=$ $g+d \times$ number of Diplodus fish where $g$ and $d$ are parameters determined by the routine. In Model (1) $m=d=0$, (2) $m=0$, (3) $d=0$, and so the models are hierarchically nested. In each analysis we used the likelihood ratio test (LRT) to determine significance of adding 1 additional parameter (for linear means and/or heteroscedasticity). Likelihood values must be $>1.92$ greater for a 4-parameter model than for a 3-parameter model to justify the inclusion of an additional parameter. As the relationship showed symptoms of unequal variation (see 'Results'), we used a quantile regression to investigate the relationship between sea urchin and Diplodus abundance. This procedure is considered as a more suitable statistical tool to analyze relationships characterized by unequal variation than the classic regression methods. The latter typically focus on estimating slopes in the mean of the response variable distribution, whereas quantile regression estimates the relations for all proportions of a probability distribution (Cade \& Noon 2003). A regression model with heterogeneous variances implies that there may be more than a single slope (i.e. rate of change) describing the relationship between response and predictor variables. Focusing exclusively on changes in the means may fail to distinguish real non-zero changes in heterogeneous distributions. Therefore, in the case of unequal variances, quantile regression estimates multiple slopes from the minimum to the maximum response, providing a more complete picture of the relationships between variables missed by other regression methods (Cade \& Noon 2003).

\section{RESULTS}

The meta-analysis showed that total fish density was on average 1.2 times greater in reserves than in fished areas $(\ln R=0.19 \pm 0.17,95 \% \mathrm{CI})$, and total fish biomass was on average 2.1 times greater in reserves 
$(\ln R=0.75 \pm 0.72,95 \% \mathrm{CI})$. In spite of the wide variability among reserves, both responses were statistically significant. However, the effects of protection varied among fish species and trophic groups (Figs. 2 \& 3). Protection caused significant increases in density and biomass of large piscivorous fish (but Dentex dentex did not show any significant response). Small piscivores showed significant increases in biomass but not density in reserves as a group, but the response differed among species. Significant increases in biomass, but not density, in reserves mean that the strongest effect of protection is an increase in individual size. All sea urchin predator species increased in both density and biomass in reserves relative to fished areas, showing little variability in the response to protection relative to that of large piscivores. As a group, invertebrate feeders Type 2 showed non-significant responses to protection, but some species, i.e. Diplodus puntazzo and Sciaena umbra, highly targeted by recreational and professional fishing, responded significantly both in terms of density and biomass. Detritivores and planktivores did not respond significantly to protection, except for the pomacentrid Chromis chromis, which seemed to respond positively, but the values of log-ratios for density and biomass were very close to zero. Sarpa salpa, the only strictly herbivorous fish in the Mediterranean, did not respond significantly to protection. It is worth noting that variability around mean responses changed among species, which could be the result of the mix between general predictable and idiosyncratic responses changing from location to location.

The contribution of protection to the total dissimilarity among fish assemblages when comparing all areas from all locations was negligible when both species (ANOSIM; global $R=-0.033, \mathrm{p}=0.77$ ) and trophic groups $(R=-0.008, \mathrm{p}=0.48)$ were considered. Conversely, the dissimilarity among fish assemblages from the different locations (regardless of the level of protection) was far higher when both fish taxa $(R=0.840$, $\mathrm{p}<0.01)$ and trophic groups $(R=0.591, \mathrm{p}<0.01)$ were considered. In other words, areas from the same location tended to be more similar, regardless of the level of protection, than reserve areas from different locations. Reserve and fished areas at Banyuls clearly separated from the other sites only when planktivorous and herbivorous fish were included in the analyses (Fig. 4). Chromis chromis, Oblada melanura, Thalas-

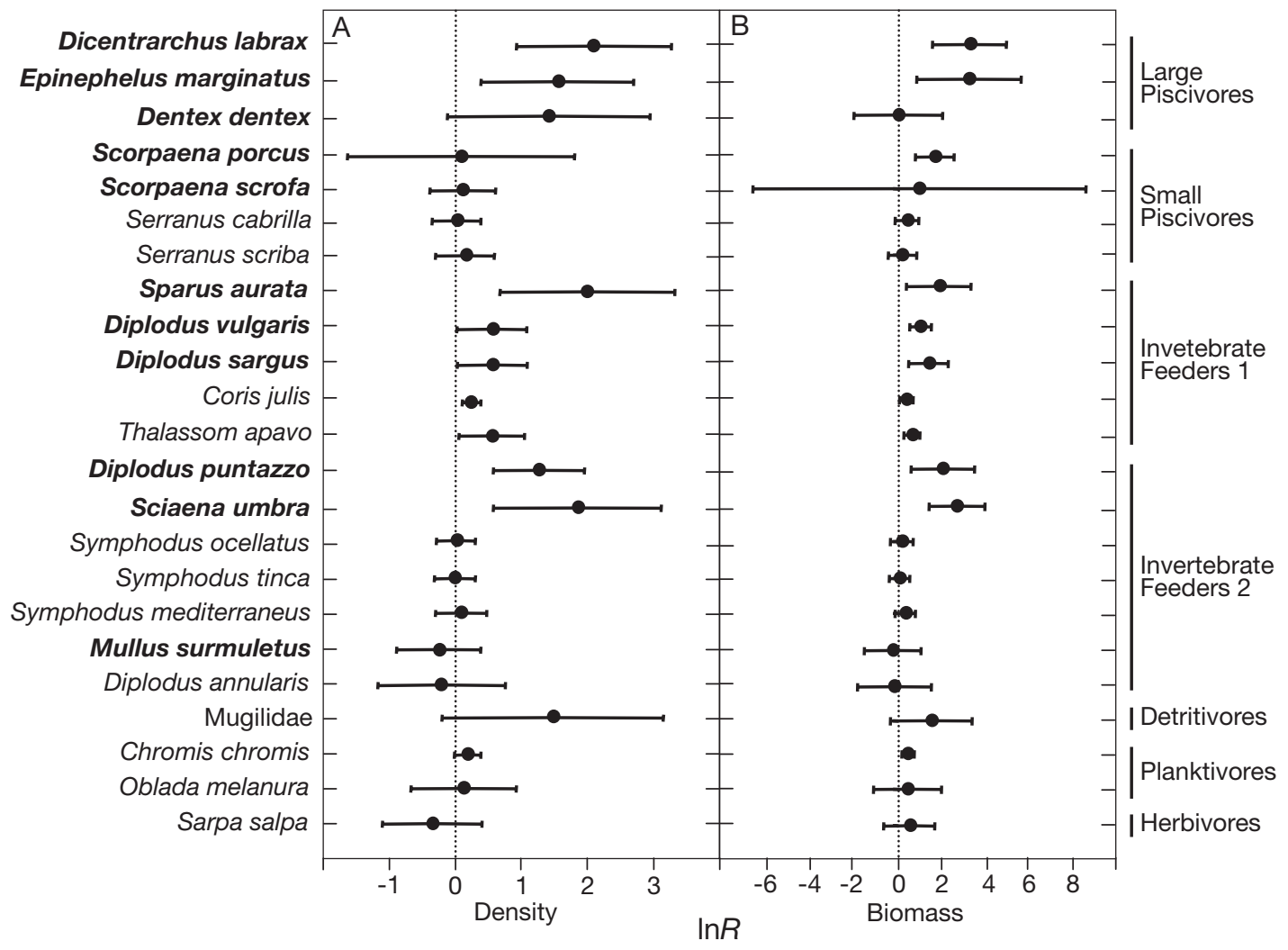

Fig. 2. Response of fish species to protection, measured as the natural log response ratio ( $\ln R$ ) of (A) density and (B) biomass between reserves and adjacent fished areas. Bars indicate $95 \% \mathrm{CI}_{i}$ fish species targeted by fishing in bold. See 'Materials and methods' for details on analysis 


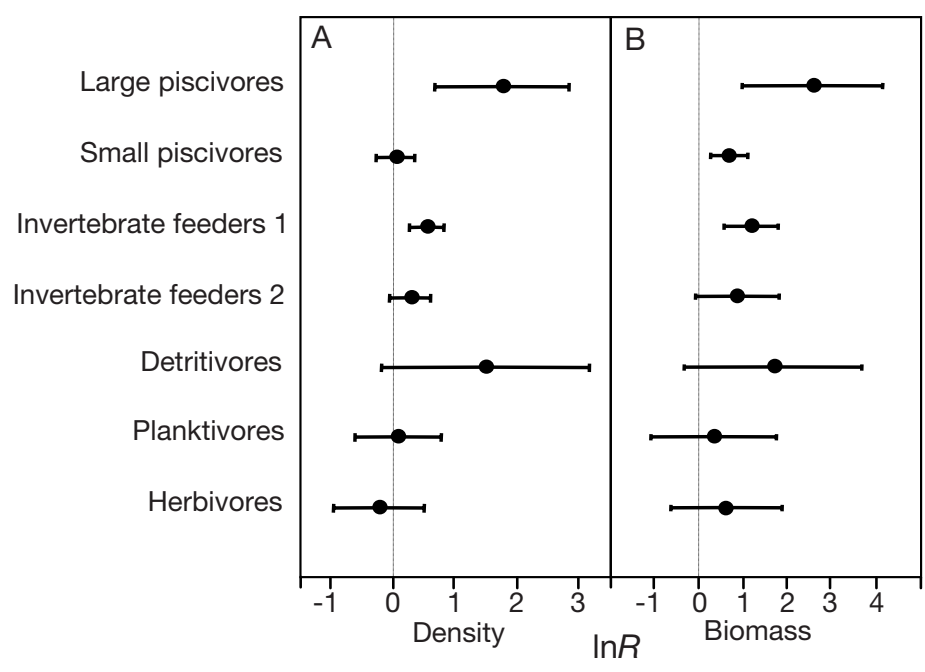

Fig. 3. Response of trophic groups of fish to protection, measured as the natural $\log$ response ratio $(\ln R)$ of $(\mathrm{A})$ density and (B) biomass between reserves and adjacent fished areas. Bars indicate $95 \%$ CI. See 'Materials and methods' for details on analysis

soma pavo, and Sarpa salpa contributed the most $(>30 \%)$ to the dissimilarity between reserves and fished areas (Table 2). The most valuable target species, the Mediterranean dusky grouper Epinephelus marginatus, made a negligible contribution to the dissimilarity, while the commercially important sea urchin predators Diplodus sargus and D. vulgaris were the most important contributors among the target species, in spite of their cumulated contribution being lower than the above-mentioned species ( 12\%; Table 2$)$. When compared with differences among locations, variation over time in the structure of fish assemblages was fairly low at Banyuls between 1980 and 1992 and Medes Islands between 1988 and 1999, in both reserves and fished areas. Surprisingly, Medes had fish assemblages more similar to those of areas located 500 to $1000 \mathrm{~km}$ away than to those of Banyuls, located $50 \mathrm{~km}$ away. Reserve and fished areas at Ustica (a relatively small island $50 \mathrm{~km}$ from the mainland) were clearly distinct from the other locations, along with Miramare (located in the Adriatic, where fish were sampled on artificial hard substrates). Therefore, similarity in fish assemblage structure among locations did not appear to be a mere function of geographic distance.

Trajectories of change in fish community structure from the fished to protected condition are shown in nMDS plots (Fig. 4). Data on species abundance showed a less clear direction of community change (i.e. 8 out of 13 arrows headed towards the right side of the plot), probably owing to different local responses of species within fish communities to protection (i.e. local

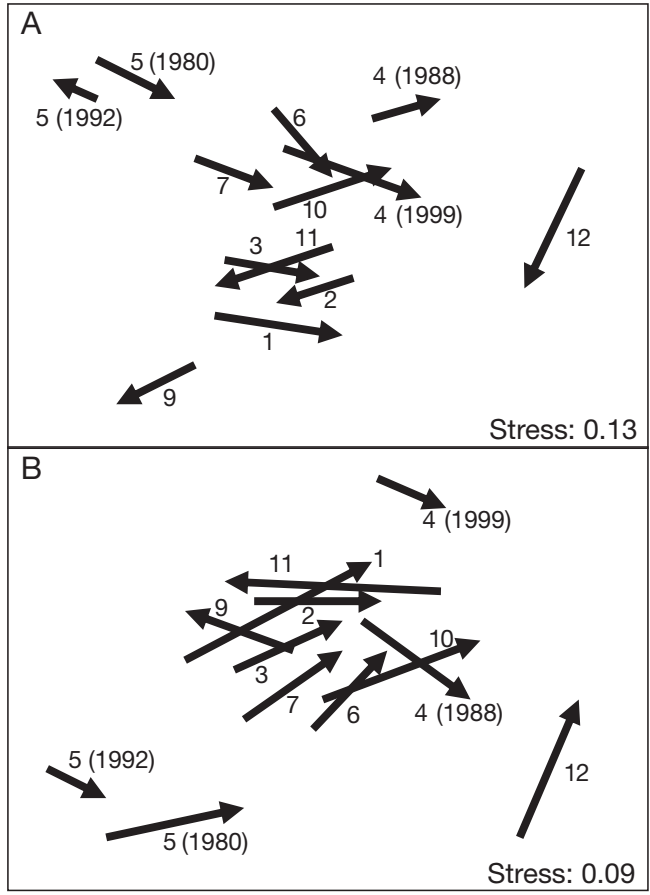

Fig. 4. Non-metric multidimensional scaling (nMDS) plots of fish density data: (A) species, (B) trophic groups. Arrows indicate change in fish communities from the fished to reserve areas. See 'Materials and methods' for details; marine reserve numbers as in Fig. 1

idiosyncratic response at species level). Instead, data on functional structure (trophic groups) showed a more consistent pattern of change (11 out of 13 arrows headed towards the right side of the plot). Although major caution and properly replicated data sets are needed to draw any conclusion, these outputs suggest

Table 2. SIMPER. Taxa and trophic groups of fish contributing most (cut-off at $55 \%$ ) to the dissimilarity between reserves (R) and fished areas (F). Invertebrate feeders Type 1: fish that eat sea urchins

\begin{tabular}{|lrrr|}
\hline & \multicolumn{4}{c|}{$\begin{array}{c}\text { Contrib. } \\
(\%)\end{array}$} & \multicolumn{1}{c|}{$\mathrm{R}$} & $\mathrm{F}$ \\
& & & \\
& & & \\
Taxa & 9.7 & 7.4 & 4.5 \\
Thalassoma pavo & 9.3 & 12.4 & 8.1 \\
Oblada melanura & 7.7 & 8.8 & 9.9 \\
Sarpa salpa & 7.5 & 127.2 & 106.2 \\
Chromis chromis & 6.8 & 21.8 & 15.7 \\
Coris julis & 6.8 & 7.1 & 4.0 \\
Diplodus sargus & 6.4 & 4.7 & 2.9 \\
Diplodus vulgaris & & & \\
Trophic groups & 21.4 & 161.8 & 123.3 \\
Planktivores & 20.9 & 9.3 & 11.1 \\
Herbivores & 16.0 & 49.8 & 31.9 \\
Invertebrate feeders Type 1 & & \\
\end{tabular}


that community changes at the species level are less predictable than changes at the functional level. In other words, these plots suggest that different species may respond differently to protection at the various reserves (reflected in inconsistent directions of response at the species level), and also that the response is more general at the trophic level because many of the species affected by protection belong to the same functional groups (especially large predators and those preying on sea urchins). Moreover, 2 vectors that did not head in the same direction as the others represent locations characterised by relatively small remote islands, which suggests that these locations may have different ecological conditions that cause a different response to protection.

Non-target trophic groups such as herbivores and planktivores were important contributors to the difference between reserves and fished areas, probably owing to their general numerical dominance regardless of the protection level. Therefore, we repeated the analyses including only trophic groups that encompassed target species (i.e. large and small piscivores and invertebrate feeders). ANOSIM showed that the contribution of protection to the total dissimilarity among fish assemblages was again negligible at both species (Global $R=-0.023, \mathrm{p}=0.64$ ) and trophic group levels $(R=-0.030, \mathrm{p}=0.21)$. In contrast, the dissimilarity among fish assemblages from the different locations was again higher at both fish species $(R=0.797, \mathrm{p}<$ $0.01)$ and trophic group levels $(R=0.442, \mathrm{p}<0.01)$. Even after excluding planktivorous and herbivorous fish (usually non-target species), areas from the same location tended to be more similar to each other, regardless of the level of protection, than were reserve areas from different locations. Fish predators that eat sea urchins (invertebrate feeders Type 1) were the

Table 3. SIMPER. Taxa and trophic groups of fish (excluding planktivores and herbivores) contributing most (cut-off at $55 \%$ ) to the dissimilarity between reserves (R) and fished areas $(\mathrm{F})$. Invertebrate feeders Type 1: fish that eat sea urchins

\begin{tabular}{|c|c|c|c|}
\hline & $\begin{array}{c}\text { Contrib. } \\
(\%)\end{array}$ & $\begin{array}{c}\text { Density } \\
\text { R }\end{array}$ & $\begin{array}{c}100 \mathrm{~m}^{-2} \text { ) } \\
\mathrm{F}\end{array}$ \\
\hline \multicolumn{4}{|l|}{ Taxa } \\
\hline Thalassoma pavo & 13.1 & 7.4 & 4.5 \\
\hline Diplodus vulgaris & 9.0 & 7.1 & 4.0 \\
\hline Coris julis & 9.0 & 21.8 & 15.7 \\
\hline Diplodus sargus & 8.5 & 4.7 & 2.9 \\
\hline Mugilidae & 6.5 & 2.1 & 0.6 \\
\hline Serranus cabrilla & 6.0 & 1.9 & 2.2 \\
\hline \multicolumn{4}{|l|}{ Trophic groups } \\
\hline Invertebrate feeders Type 1 & 28.0 & 49.7 & 31.9 \\
\hline Detritivores & 22.3 & 2.1 & 0.6 \\
\hline Small piscivores & 18.5 & 3.7 & 4.2 \\
\hline
\end{tabular}

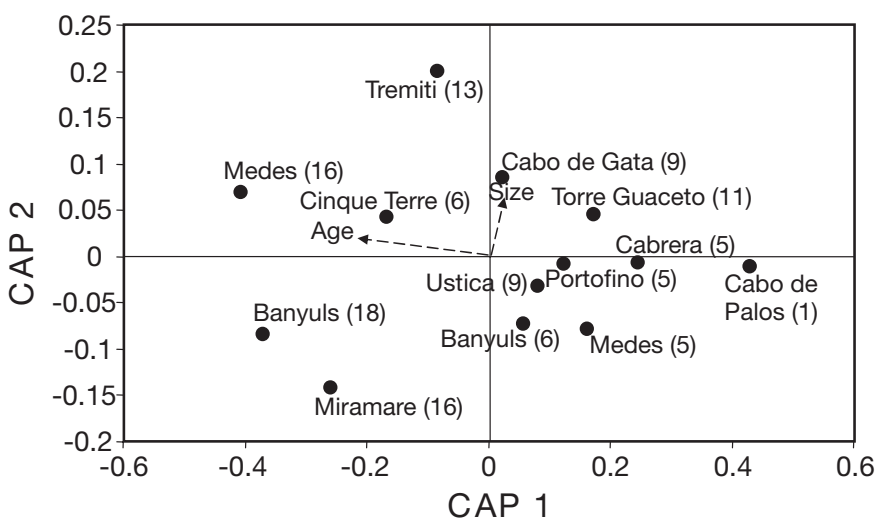

Fig. 5. Canonical correlation ordination (CAP) of fish assemblage data (trophic groups), with vectors indicating the degree of correlation of reserve age (significant; see 'Results') and size (non-significant) with canonical axes. Each point refers to a single reserve, and the number within brackets indicates reserve age at the time when data were collected

most important contributors ( 30\%) to the dissimilarity between reserve and fished areas (Table 3). Almost all areas (both reserves and fished areas) were highly interspersed among each other, except for Miramare and Medes Islands in 1999, which were clearly separated from the other sites.

The canonical correlation analysis using CAP showed that fish assemblages at the species level did not show any significant relation with reserve age (square correlation $\left.\delta^{2}=0.34, \mathrm{p}=0.53\right)$ or size $\left(\delta^{2}=0.02\right.$, $\mathrm{p}=0.23$ ). In contrast, at the functional level, fish assemblages were significantly influenced by reserve age $\left(\delta^{2}=0.73, p=0.015\right)$, whereas reserve size did not appear to be important $\left(\delta^{2}=0.09, \mathrm{p}=0.69\right)$. The bi-plot of the correlations of reserve age and size with the canonical axes provided a direct interpretation of the CAP axes in terms of the variables under study (Fig. 5). These outputs suggest that fish response to reserve age tends to be clearer when evaluated at functional (i.e. trophic group) than at species level.

As expected from the previous results, the average density of the sea urchin predators Diplodus was significantly (2.5 times) greater in reserves than in adjacent fished areas $(\ln R=0.93)$. The relationships between fish abundance and individual abundances of the sea urchins Paracentrotus lividus and Arbacia lixula were almost identical (data not shown). The LTR showed that the best-fit model for the sea urchin abundance data was heteroscedastic, with a linear decrease in SD with increasing fish abundance and a constant mean across fish densities (Table 4, Fig. 6). In other words, as fish increase in density, the variability of the realized urchin densities decreases, but not the mean (at least from a statistical point of view). Even though 
Table 4. Relationship of predatory fish-sea urchin abundance. Results of likelihood test ratio comparing 4 models of logtransformed sea urchin abundance. The best-fit model was heteroscedastic Model (2), with constant mean and SD changing linearly with fish abundance. Models using log-transformed sea urchin abundance data instead of raw data were significantly supported by the analysis. Maximum likelihood values after $10^{6}$ iterations

\begin{tabular}{|lccccc|}
\hline Model & Mean & SD & Mean (slope) & SD (slope) & Max. likelihood \\
\hline (1) Constant mean and SD & 1.389 & 1.074 & 0 & 0 & -77.514 \\
(2) Constant mean and linear SD & 1.029 & 1.536 & 0 & -0.030 & -72.106 \\
(3) Linear mean and constant SD & 1.573 & 1.057 & -0.020 & 0 & -76.683 \\
(4) Linear mean and SD & 1.284 & 1.365 & -0.005 & -0.026 & -71.363 \\
\hline
\end{tabular}

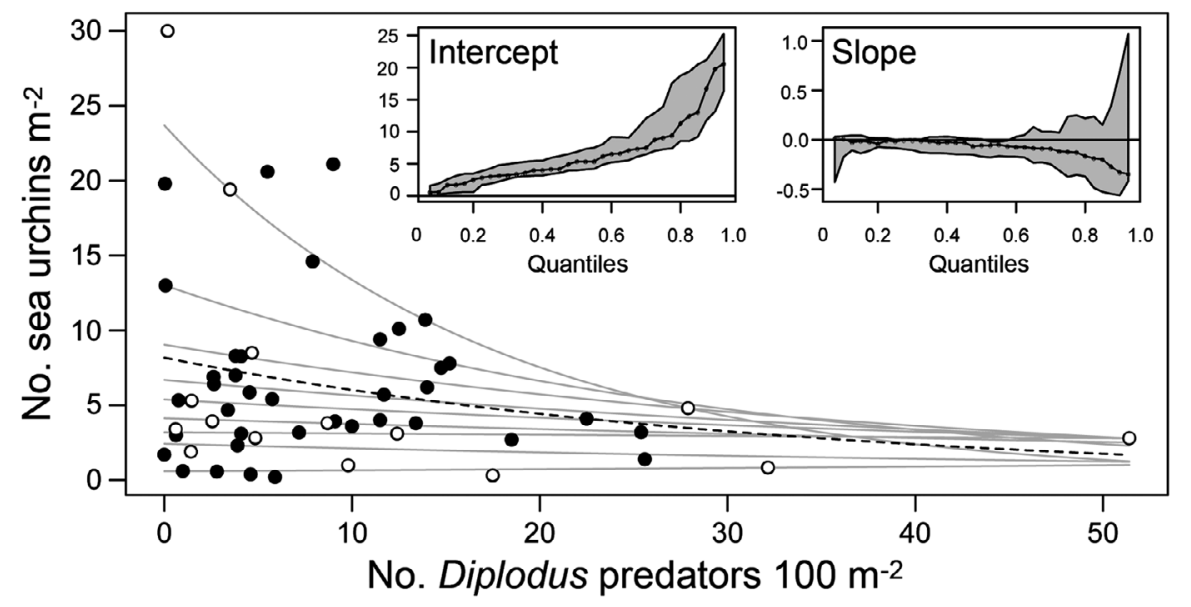

Fig. 6. Relationship between densities of sea urchins (Paracentrotus lividus and Arbacia lixula) and predatory Diplodus fish in the Mediterranean Sea. Scatterplot of $n=53$ observations of sea urchin and Diplodus predator abundances with 0.1 to 0.9 quantile (solid grey lines) and least-square (dashed line) non-linear regressions. O: Reserve areas; $\bullet$ : fished areas. Sample estimates of intercepts (small left graph) and slopes (small right graph) as a step function with $90 \%$ CI are shown

there is no specific a priori hypothesis, it is interesting to observe that sea urchin densities at sites with more than 15 Diplodus $100 \mathrm{~m}^{-2}$ had significantly lower variance than sites below this critical density (Cochran's $C$-test; $C=0.85, \mathrm{p}<0.01$ ). Within reserves this critical density of predatory fish is around 10 Diplodus $100 \mathrm{~m}^{-2}$, probably owing to the larger size (GarcíaRubies \& Zabala 1990, Harmelin et al. 1995), and therefore greater predatory efficiency, of Diplodus (Sala 1997, Hereu 2004, Guidetti 2006) in comparison to Diplodus in fished areas (Fig. 6). However, the overall density of sea urchins did not show significant differences between reserves and fished areas ( $\ln R=0.03)$.

As a result of the above-reported outcomes that provided indications of unequal variance (see Table 4), non-linear quantile regressions (the non-linear model fitted the data better than did the linear model for all quantiles >0.6) indicated that slopes-i.e. rates of change of sea urchin density in relation to fish predator abundance-were not the same across all quantiles (Table 5, Fig. 6). Slopes (i.e. the horizontal line corre- sponding to non-significant rate of change in sea urchin abundance with increasing fish predator abundance) did not differ significantly from zero for quantiles $\leq 0.5$, whereas they became progressively more negative and significant for quantiles $\geq 0.6$ (Table 5, Fig. 6). This suggests that low sea urchin density can occur with low to high density of predatory fish,

Table 5. Relationship of predatory fish-sea urchin abundance. Results of quantile regression

\begin{tabular}{|lcc|}
\hline Quantile & $\mathrm{p}$ & Slope \\
\hline 0.9 & 0.016 & -0.054 \\
0.8 & 0.042 & -0.037 \\
0.7 & 0.034 & -0.025 \\
0.6 & 0.040 & -0.021 \\
0.5 & 0.069 & -0.018 \\
0.4 & 0.199 & -0.014 \\
0.3 & 0.335 & -0.009 \\
0.2 & 0.468 & -0.009 \\
0.1 & 0.469 & -0.022 \\
\hline
\end{tabular}


whereas high sea urchin density can occur only with low Diplodus densities. In this case of unequal variances, a least-square regression would have provided a non-significant result (slope $=-0.031, \mathrm{p}=0.155$; Fig. 6), suggesting that when classic regressions (that assume homogeneous distributions) are used, an important piece of information accounting for ecological patterns can be missed. The $90 \%$ CI of estimates of intercepts and slopes (that measure the accuracy of the estimates) tended to be wider (especially for slopes) at the greater quantiles of the distribution (Fig. 6). This is consistent with the fact that the data were generated from a skewed distribution of the estimates with smaller sample size (n) in the greater quantiles, characterised by a lower probability density and thus higher sampling variation. The fact that $\mathrm{CI}$ of slopes overlap the zero value-especially for greater quantiles-suggests that major caution be taken when interpreting these results, because they were basically obtained from a regression with little power for the greater quantiles.

\section{DISCUSSION}

The response of fish species and trophic groups to protection, measured as change in abundance and biomass, showed fairly clear patterns throughout the Mediterranean Sea. As expected, the abundance of most targeted species (piscivores and some invertebrate feeders, especially fish predators of sea urchins) increased in marine reserves. In contrast, herbivores, planktivores and some predators of invertebrates, with little or no commercial value, did not show any evident response to protection, similar to the results of other studies (Jennings \& Polunin 1997, Mosquera et al. 2000, Côté et al. 2001, Micheli et al. 2004, Floeter et al. 2005). From this perspective, the present metaanalysis of the available data from Mediterranean marine reserves allowed us to provide a comprehensive quantitative picture of the response of fish species and trophic groups to protection from fishing, regardless of the fact that some studies used a poor sampling design (see 'Introduction' for details). The structure of fish assemblages (based on density data) did not reveal any clear pattern attributable to protection on a regional scale (i.e. there is no clear separation in the multidimensional space between fished and protected areas). Our results indicate that, under the size and age constraints of current Mediterranean reserves ( 1 to 18 years old; 18 to 2395 ha of no-take zone; Table 1), other (local) factors are likely to be more important than protection for explaining variability in fish assemblages among areas at the regional scale.
Reserve age is usually considered an important factor, because fish response to protection strictly depends on the relationship between life-history traits (e.g. those of slow-growing species) and duration of protection. We found that protected fish assemblages were related to reserve age when evaluated at the trophic group level, whereas no relation was found at the species level. However, it is worth noting that effective enforcement might not have begun in some of the reserves (e.g. some Italian marine reserves) at the year of formal establishment. This may bias correlations between fish assemblage trajectories and time from reserve creation. For instance, the Torre Guaceto Marine Reserve was formally established in 1991, but enforcement started to be effective around 1999, which means that the actual reserve age is 3 to $4 \mathrm{yr}$. When examining Fig. 5, Torre Guaceto not surprisingly falls within the youngest marine reserves, which reinforces our finding of a relationship between fish assemblages at functional level and reserve age.

With further regard to reserve age, Mosquera et al. (2000) did not observe any effects, Halpern \& Warner (2002) observed rapid and lasting effects, and Russ \& Alcala (2004) and Micheli et al. (2004) found that the abundance of large carnivorous fish increases in a non-saturating way for at least $25 \mathrm{yr}$ after reserve creation. The age of most of the reserves considered in the present study (at the time when the data were collected) does not encompass the life-spans of large Mediterranean piscivorous fish (e.g. groupers can live up to $50 \mathrm{yr}$ and sea breams up to $10 \mathrm{yr}^{\text {; }}$ www.fishbase. org). Our results could thus suggest that these reserves are still on their trajectories of recovery, and that none of them are likely to have reached full recovery. The above issues suggest that further effort should be invested in evaluating the effects of protection in time, provided that time is measured accurately and not simply starting from the formal establishment of marine reserves.

With regard to reserve size, this variable could theoretically affect the magnitude of the protection effect within reserves, but recent studies (e.g. Côté et al. 2001, Halpern 2003) reported that it does not dramatically affect the response of fish assemblages to protection. Our results, which suggest a minor effect of reserve size on fish assemblages, thus agree with those of the available studies (e.g. Halpern 2003) that was restricted to protection effects in the form of 'protected vs. fished' areas; other reserve effects, such as spillover (Halpern \& Warner 2003) or community recovery through changes in predatory relationships (Guidetti 2006 and references therein), could change relative to reserve size. Factors other than reserve age and size may also be important when accounting for our observed patterns. They could include small-scale gra- 
dients, patterns of larval dispersal and settlement, the physical complexity and structure of the habitat, availability of nurseries, and the local histories of exploitation of littoral ecosystems (Garcia-Charton et al. 2000 and references therein, Halpern \& Warner 2003). Although the response of some species and trophic groups to protection appears to be predictable at a local scale (with exceptions, e.g. Dentex dentex), the regional pattern of fish assemblage structure makes difficult the distinction between protected and fished areas at the regional scale. We believe that this may be explained in part by the different ages of reserves and their different successional stages at the time of sampling (e.g. Russ et al. 2005), and also by the local factors (e.g. habitat structure) demonstrated to affect fish assemblages and their distribution patterns (GarciaCharton et al. 2000).

Most previous meta-analyses of the effects of marine reserves were conducted on total density and/or biomass of fish by pooling data into broad trophic groups or families, or into target vs. non-target species. Such approaches may be inappropriate because they ignore species-level data, and families are used as a surrogate of trophic levels and target value. The family Sparidae, for instance, includes piscivores, invertebrate feeders, planktivores, and herbivores (Corbera et al. 1996). Some Sparid species are targeted by fisheries, while others have nil commercial value. In addition, the response observed when many species are included into a single taxonomic unit may be disproportionately affected by a few extremely abundant species. This suggests that, when evaluating responses to protection, the calculation of $R$ should also be performed at the lowest taxonomic level. Such an approach also accounts for biological traits typical of each species (such as movement patterns and growth rate) that can greatly influence the patterns of density and biomass in reserves vs. fished areas (Rakitin \& Kramer 1996), or the time lapse required to obtain a significant response (Russ \& Alcala 2004).

We analysed overall fish assemblages from reserves and fished areas using density, because the available information on biomass was too scarce. Planktivorous fish (usually small, gregarious, non-target species) tended to be the most conspicuous descriptors of assemblages. Many fish targeted by fisheries (e.g. piscivores and invertebrate feeders) are far larger, but their abundance is generally much lower than that of planktivorous fish. However, despite their disproportionately high abundance, planktivores did not mask the response of fish assemblages to protection. Nonetheless, the differences between reserves and fished areas would have been greater if biomass had been considered.

Our results suggest that the fish assemblage response to protection appears to be more general when functional (trophic) group is considered than when species composition is considered. Owing to the lack of proper replication for each reserve in the available data sets from published studies, it was not possible to formally (i.e. statistically) test for any specific hypothesis. However, this preliminary investigation may provide some suggestions for future studies. In fact, our results indicate that different species may respond to protection in a different way at different reserves (idiosyncratic response at species level), and that most of these species belong to the same functional categories (chiefly large predators and those preying on sea urchins). The fact that trajectories of change were different for reserves situated by relatively remote islands suggests that the different ecological conditions of these reserves may cause a different fish response to protection. This could suggest the need for different management measures (or the selection of different fish species to specifically protect) for marine reserves created in natural contexts, characterised by different ecological conditions.

Not all reserves thus showed the same trend in terms of species response. For instance, there was a general pattern of increase in the biomass of piscivores as a group in reserves, but not all species showed positive changes; in addition, in different reserves, different species were responsible for the increase in biomass. The response of the different trophic groups to protection appears to be more robust, regardless of the variability in size and age of the reserves considered in this study.

Protection and the recovery of fish assemblages may affect benthic ecosystems through cascading effects (Sala et al. 1998, Pinnegar et al. 2000). For instance, protection from fishing may allow large fish predators of sea urchins (mostly target fish) to increase in abundance and size inside reserves, in turn reducing the density of their sea urchin prey, and hence to protect macroalgal beds from overgrazing and prevent the formation of coralline barrens (McClanahan \& Sala 1997, Witman \& Dayton 2001). However, this trophic model is not general: coralline barrens or high sea urchin density may also be found within reserves (but to a lesser extent), which leads one to consider other factors - such as the role of refuges, strong recruitment events, or predation on juvenile sea urchins by predators (e.g. small fish and invertebrates) other than large fish -in regulating sea urchin populations (Sala et al. 1998, Hereu 2004, Hereu et al. 2004). Although the recovery of predators of sea urchins following the establishment of reserves is common, the transition between coralline barrens to macroalgal beds is not obvious (Sala et al. 1998, Hereu 2004, Guidetti 2006). Overfished areas may contain large-sized sea urchins and small-sized predators of sea urchins. If sea urchin 
size is such that they acquire a size refuge from predation, fish will not be able to reduce sea urchin abundance (Sala 1997, Guidetti 2006). This means that recovery at the community level may require longer time periods than the recovery of target, predatory species. Therefore, although total fish density in reserves may appear to increase and saturate within a few years (Halpern \& Warner 2002), changes in fish size and biomass, and in the whole community, involve long time periods and may go undetected in short-term studies and once-only spatial comparisons (Russ \& Alcala 2004, Russ et al. 2005). As observed by others (e.g. Shears \& Babcock 2003, Micheli et al. 2004), changes in the structure of assemblages in reserves may follow complex successional trajectories, which cannot be detected in short-term studies or snapshot comparisons.

Our results showed that the recovery of predators of sea urchin in reserves might not be large enough to contribute to the control of sea urchin populations. Findings from this study do suggest that, once predator populations exceed a certain threshold, predation can control prey populations. In contrast, when predation is weak, other factors seem to acquire greater relevance and sea urchin abundance becomes less predictable. For instance, the Ustica reserve is a small offshore, volcanic island harboring subtidal habitats mostly composed of steep and highly exposed rocky cliffs. These are not appropriate habitats for recruitment of juvenile Diplodus (García-Rubies \& Macpherson 1995, Harmelin-Vivien et al. 1995). This could account for the low average density of $D$. sargus and $D$. vulgaris both in reserve and fished areas (Vacchi et al. 1998), for large fluctuations in sea urchin populations subjected to reduced predatory control, and for the related formation of extensive sea urchin barrens ( $M$. Milazzo unpubl. data). In addition, the threshold of sea urchin predator density seems to be lower ( $<10$ Diplodus $\mathrm{m}^{-2}$ ) within reserves, where mean size of Diplodus is generally greater, than in fished areas (GarcíaRubies \& Zabala 1990, Harmelin et al. 1995, Guidetti 2006). Results indicating the relationship between predator density/size and the effectiveness of predator control upon strongly interactive prey, like sea urchins that may cause community shift from macroalgae to barrens, may have important implications for the interpretation of patterns of change at the community level within marine reserves in temperate regions. Even though we recognise that this is an a posteriori conclusion and that a specific experimental design is needed to test the hypothesis properly, this study suggests that there could be critical predator densities below which top-down control is reduced and a suite of bottom-up factors come into play, increasing variability in prey populations. This hypothesis is supported by an in- creasing number of experimental studies in marine (Sala \& Zabala 1996, Hereu 2004, Guidetti 2006) and terrestrial systems (Terborgh et al. 2001, Sala 2006).

In conclusion, this study showed that (1) establishment of marine reserves led to direct positive responses in density and biomass of predatory fish species; (2) fish assemblages did not clearly differ between protected and fished conditions at a regional scale, revealing the importance of local factors and the initial successional point of reserves; (3) the predator-prey relationship (i.e. Diplodus vs. sea urchins) at the core of the trophic cascade in the Mediterranean rocky sublittoral shows symptoms of non-linearity, suggesting that the transition between alternative states (macroalgal beds vs. barrens) could be driven by critical thresholds in the abundance of predatory fish. Overall, our findings suggest that reserves and unprotected areas should not be merely considered as 2 'treatments' in ecological studies. Instead, reserves and unprotected areas should be considered within the framework of a successional (degradation/recovery) gradient, in order to allow us to appropriately interpret the ecological changes after reserve establishment.

Acknowledgements. This study was written during P.G.'s stay at the Center for Marine Biodiversity and Conservation at Scripps Institution of Oceanography, as part of his $\mathrm{PhD}$, and represents a contribution towards the aims of MARBEF (EU Network of Excellence on 'Marine Biodiversity and Ecosystem Functioning' under EU-Framework Programme 6) and ECOFISHMOD (POR-Regione Puglia project). Some unpublished data were kindly provided by P. Francour, J. Harmelin and S. Ruitton (France); F. Badalamenti, F. Micheli, M. Milazzo, M. Mori and L. Tunesi (Italy); and J. Coll, A. GarcíaRubies and B. Hereu (Spain), to whom we are very grateful. Thanks to S. Sandin, M. Anderson, A. Terlizzi and L. Ciannelli who helped with statistical analyses, and to B. Halpern and N. Holland who revised and improved an earlier version of the manuscript.

\section{LITERATURE CITED}

Anderson MJ, Willis TJ (2003) Canonical analysis of principal coordinates: a useful method of constrained ordination for ecology. Ecology 84:511-525

Bell J (1983) Effects of depth and marine reserve fishing restrictions on the structure of a rocky reef fish assemblage in the north-western Mediterranean Sea. J Appl Ecol 20:357-369

Cade BS, Noon BR (2003) A gentle introduction to quantile regression for ecologists. Front Ecol Environ 1:412-420

Clarke KR, Warwick RM (1994) Change in marine communities: an approach to statistical analysis and interpretation. Natural Environment Research Council, Plymouth

Corbera J, Sabatés A, García-Rubies A (1996) Peces de mar de la Península Ibérica. Planeta, Barcelona

Côté IM, Mosquera I, Reynolds JD (2001) Effects of marine reserves characteristics on the protection of fish populations: a meta-analysis. J Fish Biol 59:178-189

Dufour V, Jouvenel JY, Galzin R (1995) Study of a Mediter- 
ranean reef fish assemblage. Comparisons of population distributions between depths in protected and unprotected areas over one decade. Aquat Liv Resour 8:17-25

Edgar GJ, Barrett NS (1999) Effects of the declaration of marine reserves on Tasmanian reef fishes, invertebrates and plants. J Exp Mar Biol Ecol 242:107-144

Fischer W, Bauchot ML, Schneider M (1987) Fiches FAO d'identification des éspèces pour les besoins de la pêche. Méditerranée et Mer Noire, Zone 37. II Vertebrés. FAO, Rome

Floeter SR, Halpern BS, Ferreira CEL (2005) Effects of fishing and protection on Brazilian reef fishes. Conserv Biol 128: 391-402

Francour P (1990) Dynamique de l'écosystème à Posidonia oceanica dans le parc national de Port-Cros. Analyse des compartiments matte, litière, faune vagile, échinodermes et poissons. Doctorat d'Université, Université de Paris VI

Francour P (1991) The effect of protection level on a coastal fish community at Scandola, Corsica. Rev Ecol Terre Vie 46:65-81

Francour P (1994) Pluriannual analysis of the reserve effect on ichthyofauna in the Scandola natural reserve (Corsica, Northwestern Mediterranean). Oceanol Acta 17:309-317

Garcìa-Charton JA, Williams ID, Pérez-Ruzafa A, Milazzo M and 5 others (2000) Evaluating the ecological effects of Mediterranean marine protected areas: habitat, scale and the natural variability of ecosystems. Environ Cons 27: 159-178

Garcì-Charton JA, Pérez-Ruzafa A, Sànchez-Jerez P, BayleSempere JT, Reñones O, Moreno D (2004) Multi-scale spatial heterogeneity, habitat structure, and the effect of marine reserves on Western Mediterranean rocky reef fish assemblages. Mar Biol 144:161-182

García-Rubies A, Macpherson E (1995) Substrate use and temporal pattern of recruitment in juvenile fishes of the Mediterranean littoral. Mar Biol 124:35-42

García-Rubies A, Zabala M (1990) Effects of total fishing prohibition on the rocky fish assemblages of Medes Islands marine reserve (NW Mediterranean). Sci Mar 54:317-328

Guidetti P (2002) Mediterranean MPAs: the importance of experimental design in detecting the effects of protection measures on fish. Aquat Conserv 12:619-634

Guidetti P (2006) Marine reserves re-establish lost predatory interactions and cause community-wide changes in rockyreefs. Ecol Appl 16:963-976

Guidetti P, Bussotti S (2000) Nearshore fish assemblages associated with shallow rocky habitats along the southern Croatian coast (Eastern Adriatic Sea). Vie Milieu 50: 171-176

Guidetti P, Fraschetti S, Terlizzi A, Boero F (2003) Distribution patterns of sea urchins and barrens in shallow Mediterranean rocky reefs impacted by the illegal fishery of the boring mollusc Lithophaga lithophaga. Mar Biol 143: 1135-1142

Guidetti P, Verginella L, Viva C, Odorico R, Boero F (2005) Protection effects on fish assemblages, and comparison of two visual-census in shallow artificial rocky habitats in the northern Adriatic Sea. J Mar Biol Assoc UK 85:247-255

Halpern BS (2003) The impact of marine reserves: do reserves work and does reserve size matter? Ecol Appl 13:117-137

Halpern BS, Warner RR (2002) Marine reserves have rapid and lasting effects. Ecol Lett 5:361-366

Halpern BS, Warner RR (2003) Matching marine reserve design to reserve objectives. Proc R Soc Lond B 270: 1871-1878

Harmelin JG (1987) Structure et variabilité de l'ichtyofaune d'une zone rocheuse protégée en Méditerranée (Parc national de Port-Cros, France). Mar Ecol 8:263-284

Harmelin JG, Bachet F, García F (1995) Mediterranean marine reserves: fish indices as tests of protection efficiency. PSZN I: Mar Ecol 16:233-250

Harmelin-Vivien ML, Harmelin JG, Chauvet C, Duval C and 7 others (1985) Evaluation des peuplements et populations de poissons. Méthodes et problemes. Rev Ecol Terre Vie 40:467-539

Harmelin-Vivien ML, Harmelin JG, Leboulleux V (1995) Microhabitat requirements for settlement of juvenile sparid fishes on Mediterranean rocky shores. Hydrobiologia 300/301:309-320

Hedges LV, Olkin I (1985) Statistical methods for metaanalysis. Academic Press, New York

Hereu B (2004) The role of trophic interactions between fishes, sea urchins and algae in the northwestern Mediterranean rocky infralittoral. $\mathrm{PhD}$ thesis, Universitat de Barcelona

Hereu B, Zabala M, Linares C, Sala E (2004) Temporal and spatial variability in settlement of the sea urchin Paracentrotus lividus in the NW Mediterranean. Mar Biol 144: 1011-1018

Hurlbert SH (1984) Pseudoreplication and the design of ecological field experiments. Ecol Monogr 54:187-211

Jennings S, Polunin NCV (1997) Impacts of predator depletion by fishing on the biomass and diversity of non-target reef fish communities. Coral Reefs 16:71-82

Jennings S, Grandcourt EM, Polunin NCV (1995) The effects of fishing on the diversity, biomass and trophic structure of Seychelles' reef fish communities. Coral Reefs 14:225-235

Lecchini D, Lenfant P, Planes S (2002) Variation in abundance and population dynamics of the sea urchin Paracentrotus lividus on the Catalan coast (north-western Mediterranean Sea) in relation to habitat and marine reserve. Vie Milieu 52:111-118

McClanahan TR, Sala E (1997) A Mediterranean rocky-bottom ecosystem fisheries model. Ecol Model 104:145-164

Micheli F (1999) Eutrophication, fisheries, and consumerresource dynamics in marine pelagic ecosystems. Science 285:1396-1398

Micheli F, Halpern BS, Botsford LW, Warner RR (2004) Trajectories and correlates of community change in no-take marine reserves. Ecol Appl 14:1709-1723

Micheli F, Benedetti-Cecchi L, Gambaccini S, Bertocci I, Borsini C, Osio GC, Romano F (2005) Alternate states, marine protected areas, and the structure of Mediterranean rocky-reef assemblages. Ecol Monogr 75:81-102

Mosquera I, Côté IM, Jennings S, Reynolds JD (2000) Conservation benefits of marine reserves for fish populations. Anim Conserv 4:321-332

Pauly D, Christensen V, Dalsgaard J, Froese R, Torres F Jr (1998) Fishing down marine food webs. Science 279: 860-863

Pinnegar JK, Polunin NVC, Francour P, Badalamenti F and 7 others (2000) Trophic cascades in benthic marine ecosystems: lessons for fisheries and protected-area management. Environ Conserv 27:179-200

Rakitin A, Kramer DL (1996) Effect of a marine reserve on the distribution of coral reef fishes in Barbados. Mar Ecol Prog Ser 131:97-113

Russ GR, Alcala AC (2004) Marine reserves: long-term protection is required for full recovery of predatory fish populations. Oecologia 138:622-627

Russ GR, Stockwell B, Alcala AC (2005) Inferring versus measuring rates of recovery in no-take marine reserves. Mar Ecol Prog Ser 292:1-12

Sala E (1997) Fish predators and scavengers of the sea urchin 
Paracentrotus lividus in protected areas of the north-western Mediterranean Sea. Mar Biol 129:531-539

Sala E (2004) The past and present topology and structure of Mediterranean subtidal rocky-shore food webs. Ecosystems 7:333-340

Sala E (2006) Top predators provide insurance against climate change. Trends Ecol Evol 21:479-480

Sala E, Zabala M (1996) Fish predation and the structure of the sea urchin Paracentrotus lividus populations in the NW Mediterranean. Mar Ecol Prog Ser 140:71-81

Sala E, Boudouresque CF, Harmelin-Vivien M (1998) Fishing, trophic cascades, and the structure of algal assemblages: evaluation of an old but untested paradigm. Oikos 82: 425-439

Shears NT, Babcock RC (2002) Marine reserve demonstrate top-down control of community structure on temperate reefs. Oecologia 132:131-142

Shears NT, Babcock RC (2003) Continuing trophic cascade effects after 25 years of no-take marine reserve protection. Mar Ecol Prog Ser 246:1-16

Terborgh J, Lopez L, Nuñez P, Rao M and 7 others (2001) Ecological meltdown in predator-free forest fragments. Science 294:1923-1926

Tunesi L, Molinari A (2005) Species richness and biogeo-

Editorial responsibility: Otto Kinne (Editor-in-Chief),

Oldendorf/Luhe, Germany graphic outlines of the fish assemblage of the Portofino Marine Protected Area (Ligurian Sea). Biol Mar Mediterr 12:116-123

Tunesi L, Molinari A, Salvati E (2006) Fish assemblage of the marine protected area of Cinque Terre (NW Mediterranean Sea): first characterization and assessment by visual census. Chem Ecol (Suppl) 22:245-253

Vacchi M, Bussotti S, Guidetti P, La Mesa G (1998) Study on the coastal fish assemblage in Ustica Island's Marine Reserve (Southern Tyrrhenian Sea). Ital J Zool 65: 281-286

Verlaque M (1987) Relations entre Paracentrotus lividus (Lamarck) et le phytobenthos de Mediterranée occidentale. In: Boudouresque CF (ed) Colloque international sur Paracentrotus lividus et les oursins comestibles. GIS Posidonie, Marseille, p 5-36

Willis TJ, Millar RB, Babcock RC (2003) Protection of exploited fish in temperate regions: high density and biomass of snapper Pagrus auratus (Sparidae) in northern New Zealand marine reserves. J Appl Ecol 40:214-227

Witman JD, Dayton PK (2001) Rocky subtidal communities. In: Bertness MD, Gaines SD, Hay ME (eds) Marine community ecology. Sinauer Associates, Sunderland, MA, p 339-366

Submitted: November 3, 2005; Accepted: December 8, 2006 Proofs received from author(s): March 6, 2007 